\title{
Seasonal variation in the month of birth in patients with skin cancer
}

\author{
F La Rosa ${ }^{1}$, A Liso ${ }^{2}$, F Bianconi ${ }^{1}$, E Duca $^{3}$ and F Stracci ${ }^{*}, 1$ \\ ${ }^{1}$ Department of Experimental Medicine, Public Health Section, University of Perugia, 06126 Perugia, Italy; ${ }^{2}$ Department of \\ Medicine and Surgery, University of Foggia, 71122 Foggia, Italy and ${ }^{3}$ Department of Health, Regional Government of Umbria, \\ 06124 Perugia, Italy
}

Background: Month of birth influences the risk of developing several diseases. We investigated the influence of date of birth on melanoma skin cancer (MSC) and non-melanoma skin cancer (NMSC) incidence.

Methods: Enhanced cancer registry data were analysed including 1751 MSC and 15200 NMSC.

Results: People born in February to April showed significantly elevated risks of NMSC compared with those born in summertime.

Conclusions: We demonstrated seasonality by date of birth for skin cancer incidence. Neonatal UV exposure may explain this finding.

Date of birth has been associated with health outcomes, including multiple sclerosis, autism, schizophrenia, and life expectancy (Davies et al, 2003; Zerbo et al, 2011; Dobson et al, 2013; Ueda et al, 2013).

The seasonality of birth and cancer risk was reported among teenagers and young adults for haematological or brain cancers and, in adults, for breast or central nervous system cancers (Yuen et al, 1994; Kristoffersen and Hartveit, 2000; Koch et al, 2006; Schmidt et al, 2009; Staykov et al, 2009; Parodi et al, 2013; Van Laar et al, 2013; Crump et al, 2014a) The reason for the association remains unclear. However, seasonal variation of exposure to environmental factors has been often proposed to explain the observed risk patterns (Currie and Schwandt, 2013).

In the Umbria region of Italy, non-melanoma skin cancer (NMSC) is the most frequent cancer site. The standardized skin cancer incidence rates were increasing in the study period (1994-2010; Data are available at http://www.rtup.unipg.it/). Similar trends were reported for many western countries (Erdmann et al, 2013; Nikolaou and Stratigos, 2014). Explanations proposed for the observed trend include increased exposure to risk factors (for example, sun exposure) and increasing skin examination for the early diagnosis of melanoma (Bataille and de Vries, 2008). Seasonal effects can contribute to define the role of risk factor exposures in determining actual incidence patterns and trends.
The goal of this paper is to investigate the influence of date of birth on skin cancer incidence.

\section{MATERIALS AND METHODS}

The Umbrian Cancer Registry (RTUP) covers all residents of Umbria, Italy (that is, 900000 inhabitants). Cases were collected in accordance with standard methods for cancer registries. RTUP is a member of the International Association of Cancer Registries and contributor of the international publication of incidence data (Forman et al, 2013). RTUP has a high data quality standard. Very low percentages of incomplete cases known only from causes of death certification are achieved through extensive search in the data sources and trace-back including search of information by family physicians. Cancer type and site were coded using the ICD10 (WHO, 1992). Cancer registry data were managed according to Italian laws and rules for cancer registries.

We performed an additional search for cases among all regional dermatologists and dermatopathologists to ensure completeness. The information system of the Umbria Cancer Registry (S.G.RTUP) was used for data management (Bianconi et al, 2012).

The incidence rate was calculated per 100000 residents per year.

Because of the relatively small number of cases, the incidence of melanoma was examined for both sexes on the whole.

*Correspondence: Professor F Stracci; E-mail: fabrizio.stracci@unipg.it

Received 15 March 2014; revised 15 August 2014; accepted 7 September 2014;

published online 7 October 2014

(c) 2014 Cancer Research UK. All rights reserved 0007-0920/14

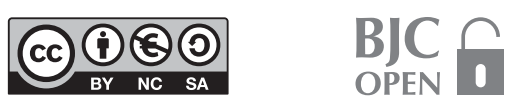


The statistical evaluation of seasonality on monthly data, adjusted for varying population at risk, was carried out by the Walter and Elwood test (Walter and Elwood, 1975). The $\chi^{2}$ test was used to compare distributions by gender.

To investigate the association between incidence and diagnosis or birth month, we used negative binomial regression. Nested models were compared using the likelihood ratio test.

A spline was used to describe the correlation between birth and skin cancer incidence. We used weekly data to obtain a better approximation of the function to the observed risks (Royston and Sauerbrei, 2007).

All tests were two-sided and results with $P<0.05$ were considered significant.

\section{RESULTS}

In the study period, 1745 cases of melanoma (50\% females) and 15992 of carcinoma ( $41 \%$ females, $66 \%$ basal-cell cancers) were registered.

The NMSC monthly distribution of incidence showed a clear seasonality (see Supplementary Figure 1). The risk shape for melanoma skin cancer (MSC) cases was similar to NMSC with the exception of the high incidence rate for those born in June. Seasonal trends were statically significant for NMSC (see Supplementary Table 1) and nonsignificant for MSC patients $(P=0.09)$.

The monthly distribution by gender for NMSC patients was not statistically different $\left(\chi^{2} P=0.4\right)$.

We fitted separate negative binomial regression models by cancer type (that is, melanoma of the skin, NMSCs) for the month of birth (Table 1). This allows inspection and comparison of relative risks without constraint on seasonal pattern. NMSC was also divided into basal cell- and squamous-cell cancers, and separate analyses were performed for these morphologies (see Supplementary Materials). Monthly distribution by skin cancer type was not significantly different.

A flexible model (that is, restricted cubic spline) was fitted to further illustrate skin cancer risk as a continuous function of date of birth (Figure 1). A single spline was used for MSC and NMSC, assuming a common underling risk function. Observed MSC and NMSC rates were plotted together with splines to provide a visual

Table 1. Negative binomial regression models for NMSC and MSC cancers by month of birth

\begin{tabular}{|c|c|c|c|c|c|c|c|c|}
\hline & \multicolumn{4}{|c|}{ NMSC (C44) } & \multicolumn{4}{|c|}{ MSC (C43) } \\
\hline Variable & IRR & \multicolumn{2}{|c|}{$95 \% \mathrm{Cl}$} & $P$ & IRR & \multicolumn{2}{|c|}{$95 \% \mathrm{Cl}$} & $P$ \\
\hline \multicolumn{9}{|l|}{ Months } \\
\hline January & 1.18 & 1.09 & 1.28 & $<0.001$ & 1.41 & 1.12 & 1.77 & 0.003 \\
\hline February & 1.29 & 1.19 & 1.39 & $<0.001$ & 1.15 & 0.90 & 1.47 & 0.25 \\
\hline March & 1.30 & 1.20 & 1.40 & $<0.001$ & 1.36 & 1.09 & 1.71 & 0.007 \\
\hline April & 1.31 & 1.21 & 1.41 & $<0.001$ & 1.15 & 0.90 & 1.45 & 0.26 \\
\hline May & 1.14 & 1.05 & 1.23 & 0.002 & 1.15 & 0.90 & 1.46 & 0.26 \\
\hline June & 1.02 & 0.93 & 1.11 & 0.70 & 1.41 & 1.11 & 1.77 & 0.004 \\
\hline July ${ }^{a}$ & Ref. & & & & Ref. & & & \\
\hline August & 1.04 & 0.96 & 1.13 & 0.32 & 1.12 & 0.88 & 1.43 & 0.36 \\
\hline September & 1.09 & 1.00 & 1.18 & 0.04 & 1.14 & 0.90 & 1.46 & 0.28 \\
\hline October & 1.08 & 1.00 & 1.17 & 0.06 & 1.10 & 0.86 & 1.40 & 0.45 \\
\hline November & 1.20 & 1.11 & 1.31 & $<0.001$ & 1.12 & 0.87 & 1.43 & 0.37 \\
\hline December & 1.11 & 1.02 & 1.21 & 0.01 & 0.93 & 0.72 & 1.21 & 0.61 \\
\hline \multicolumn{9}{|l|}{ Gender } \\
\hline $\begin{array}{l}\text { Males } \\
\text { Females }\end{array}$ & $\begin{array}{l}\text { Ref. } \\
0.66\end{array}$ & 0.64 & 0.68 & $<0.001$ & $\begin{array}{l}\text { Ref. } \\
0.95\end{array}$ & 0.86 & 1.04 & 0.25 \\
\hline \multicolumn{9}{|c|}{$\begin{array}{l}\text { Abbreviations: } \mathrm{Cl}=\text { confidence interval; } I R R=\text { incidence rate ratio; } \mathrm{MSC}=\text { melanoma skin } \\
\text { cancer; } \mathrm{NMSC}=\text { non-melanoma skin cancer; Ref. = reference category. } \\
\mathrm{a}_{\text {reference category is the month with the lowest date of birth. }}\end{array}$} \\
\hline
\end{tabular}

comparison of the continuous risk function to observed data. The curve gave evidence of a clear excess risk for people born in the first months of the year. Indeed the curves for melanoma, squamous cell, and basal cell cancers were very similar (Figure 2). The curve for melanoma was not significant and was shown only to illustrate the marked similarity with the other skin cancer morphologies.

\section{DISCUSSION}

We observed a strong seasonal effect of the date of birth that influenced incidence of skin cancers. Our study is based on a homogeneous population that has been remarkably stable for decades and, thereby, has a common genetic background and widespread social habits.

Two studies demonstrated the influence of birth date on MSC risk (Basta et al, 2011, Crump et al, 2014b) and none is available for NMSC.

In our study, the influence of month of birth was clear for NMSC and was borderline nonsignificant for MSC cancer. However, the MSC incidence pattern did not differ significantly

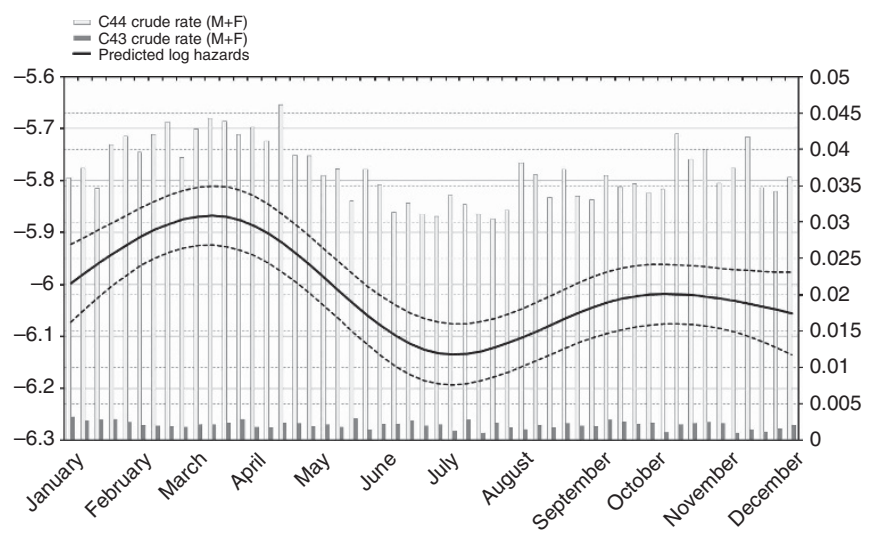

Figure 1. Weekly skin cancer risk. Curves represent skin cancer risk adjusted by gender, site and population at risk (dashed lines $95 \%$ confidence interval). Bars are MSC (solid) and NMSC (hollow) crude incidence rates.
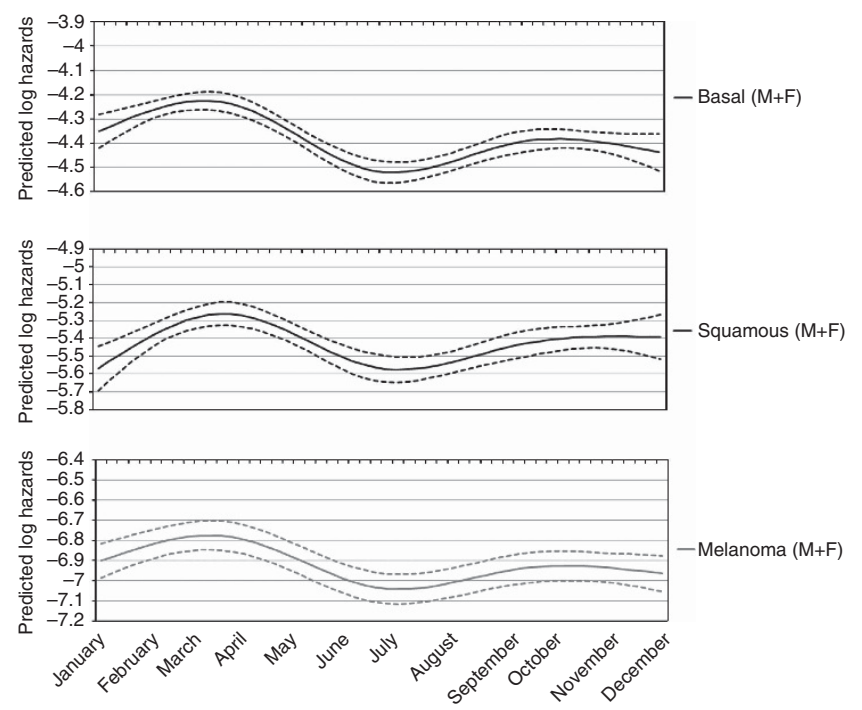

Figure 2. Weekly skin cancer risk by morphology (top: Basal cells cancer, middle: squamous cells cancer and bottom: melanoma). 
from that of NMSC so that we can assume and discuss a common risk shape. A recent cohort study found evidence of high risk of adult MSC for persons born during spring (Crump et al, 2014b). We observed highest risks for people born in March-April as in the study by Crump et al. The small difference in the curves shape depends on the use of a less-flexible model (that is, sinusoidal logistic regression) in the study by Crump et al. The curves by morphology showed a marked similarity. However, squamous-cell cancer has been linked with a different UV exposure pattern with respect to basal-cell skin cancer and melanoma (English et al, 1997). Our result is compatible with a role of very early exposures in determining an increased susceptibility to all skin cancers. Subsequent UV exposures influence the development of MSC, basal cell, or squamous cell cancers.

The seasonal pattern for NMSC could be explained with UV exposure in utero or in the first months of life.

Several authors have examined the influence of UV exposure both on human lifespan and on the frequency of diseases such as diabetes, multiple sclerosis, and so on (Menni et al, 2012; Davis and Lowell, 2013). Lowell and Davis (2010) wrote that 'the hypothesis that specific wavelengths of UVR, experienced at critical times in development as at conception or early gestation, and with specific intensity or rate of change, modulates the expression of human diseases'.

In addition, very early-life UV exposure could increase the risk of skin cancer occurrence many years later, if we assume that direct sun exposure in summertime is avoided in newborns ( $0-3$ months) and that children 4-6 months old are exposed more than younger ones. Indeed, the study by Stanton et al (2000) gave evidence of increasing sun exposure with age, comparing infants (that is, $<1$ year of age) with toddlers (2- to 4 -year-old children).

UV skin exposure is widely accepted to be a risk factor for MSC and NMSC (D'Orazio et al, 2013) and early exposure has been associated with incidence of melanoma in the young (Basta et al, 2011).

Neonatal skin is immature and still developing through the first year of life (Nikolovski et al, 2008). Biological mechanisms have been proposed to explain the relationship between neonatal UV exposure and adult cancer risk. Exposures of the immature skin occurring in the first weeks after birth tend to induce tolerance and have a lasting influence on the immune system in mice (McGee et al, 2011).

Other possible explanations include in utero or early exposures to nutritional, infective, or environmental factors other than UV. Vitamin D levels depend on both dietary intake and UV exposure and have been proposed as an explanation for the association between season of birth and risk of adult disease (Bersani et al, 2006; Crump et al, 2014a).

Skin cancers pose a problem of completeness to cancer registries. Surgical treatment can be performed without hospitalisation, and histological verification can be carried out by a dermatopathologist, thereby not resulting in any cancer registry data sources (Cockburn et al, 2008). Many cancer registries do not collect NMSC data at all because additional data sources are needed to ensure completeness of registration (Lomas et al, 2012). We performed an additional active search for cases among all regional dermatologists and regularly acquire archives from dermatopathologists to avoid incompleteness of registration.

In conclusion, our study provides evidence of a seasonal influence of month of birth on skin cancer incidence. UV exposure of the neonatal skin or in utero may increase susceptibility to both MSC and NMSC during adulthood.

Therefore, studies to further (Stanton et al, 2000) characterise the pattern of sun exposure during pregnancy and in the first months of life would be important in order to investigate the possible role of UV exposure on the risk of skin cancer in adulthood.

\section{ACKNOWLEDGEMENTS}

This work was supported by the Department of Health, Regional Government of Umbria. We gratefully thank Katherine Brandt for English language review and Francesca Massenzio for editorial assistance.

\section{REFERENCES}

Basta NO, James RW, Craft AW, McNally RJQ (2011) Seasonality variation in the month of birth in teenagers and young adults with melanoma suggests the involvement of early-life exposure. Pigment Cell Melanoma Res 24: 250-253.

Bataille V, de Vries E (2008) Melanoma-Part 1: epidemiology, risk factors, and prevention. BMJ 337: a2249.

Bersani G, Pucci D, Gherardelli S, Conforti F, Bersani I, Osborn JF, Hansen V, Pancheri P. (2006) Excess in the spring and deficit in the autumn in birth rates of male schizophrenic patients in Italy: potential role of perinatal risk factors. J Matern Fetal Neonatal Med 19: 425-431.

Bianconi F, Brunori V, Valigi P, La Rosa F, Stracci F. (2012) Information technology as tools for cancer registry and regional cancer network integration. IEEE Trans Syst Man Cybern A Syst Hum 42: 1410-1424.

Cockburn M, Swetter SM, Peng D, Keegan TH, Deapen D, Clarke CA. (2008) Melanoma underreporting: why does it happen, how big is the problem, and how do we fix it? J Am Acad Dermatol 59: 1081-1085.

Crump C, Sundquist J, Sieh W, Winkleby MA, Sundquist K. (2014a) Season of birth and risk of Hodgkin and non-Hodgkin lymphoma. Int J Cancer 135: 2735-2739.

Crump C, Sundquist K, Sieh W, Winkleby MA, Sundquist J. (2014b) Season of birth and other perinatal risk factors for melanoma. Int J Epidemiol 43: 793-801.

Currie J, Schwandt H. (2013) Within-mother analysis of seasonal patterns in health at birth. Proc Natl Acad Sci USA 110: 12265-12270.

Davies G, Welham J, Chant D, Torrey EF, McGrath J. (2003) A systematic review and meta-analysis of Northern Hemisphere season of birth studies in schizophrenia. Schizophr Bull 29: 587-593.

Davis GE, Lowell WE. (2013) Variation in ultraviolet radiation and diabetes: evidence of and epigenetic effect that modulates diabetics' lifespan. Clin Epigenetics 5: 5.

Dobson R, Giovannoni G, Ramagopalan S. (2013) The month of birth effect in multiple sclerosis: systematic review, meta-analysis and effect of latitude. J Neurol Neurosurg Psychiatry 84: 427-432.

D'Orazio J, Jarrett S, Amaro-Ortiz A, Scott T. (2013) UV Radiation and the Skin. Int J Mol Sci 14: 12222-12248.

English DR, Armstrong BK, Kricker A, Fleming C. (1997) Sunlight and cancer. Cancer Causes Control 8: 271-283.

Erdmann F, Lortet-Tieulent J, Schüz J, Zeeb H, Greinert R, Breitbart EW, Bray F. (2013) International trends in the incidence of malignant melanoma 1953-2008-are recent generations at higher or lower risk? Int J Cancer 132: 385-400.

Forman D, Bray F, Brewster DH, GombeMbalawa C, Kohler B, Piñeros M, Steliarova-Foucher E, Swaminathan R, Ferlay J eds. (2013) Cancer Incidence in Five Continents, $X$ (electronic version). IARC: Lyon. http://ci5.iarc.fr (last accessed on 10 August 2014).

Koch HJ, Klinkhammer-Schalke M, Hofstädter F, Bogdahn U, Hau P (2006) Seasonal patterns of birth in patients with glioblastoma. Chronobiol Int 23: 1047-1052.

Kristoffersen S, Hartveit F. (2000) Is a woman's date of birth related to her risk of developing breast cancer? Oncol Rep 7: 245-247.

Lomas A, Leonardi-Bee J, Bath-Hextall F. (2012) A systematic review of worldwide incidence of nonmelanoma skin cancer. $\mathrm{Br} J$ Dermatol 166: 1069-1080.

Lowell WE, Davis GE. (2010) The effects of solar cycles on human lifespan in the 50 United States: variation in light affects the human genome. Med Hypotheses 75: 17-25.

McGee HM, Malley RC, Muller HK, Woods GM. (2011) Neonatal exposure to UVR alters skin immune system development, and suppresses immunity in adulthood. Immunol Cell Biol 89: 767-776.

Menni C, Lowell WE, Bentzen J, Bergamaschi R, Martinelli Boneschi F, Martinelli V, Bernardinelli L, Stenager E, Davis Jr GE, Foco L. (2012) 
Short and long term variation in ultraviolet variation and multiple sclerosis. Int J Environ Res Public Health 9: 685-697.

Nikolaou V, Stratigos AJ. Emerging trends in the epidemiology of melanoma (2014) Br J Dermatol 170: 11-19.

Nikolovski J, Stamatas GN, Kollias N, Wiegand BC. (2008) Barrier function and water-holding and transport properties of infant stratum corneum are different from adult and continue to develop through the first year of life. J Invest Dermatol 128: 1728-1736.

Parodi S, Fontana V, Haupt R, Corrias MV. (2013) Seasonal variations of date of diagnosis and birth for neuroblastoma patients in Italy. Cancer Epidemiol 37: 575-578.

Royston P, Sauerbrei W (2007) Multivariable modelling with cubic regression splines: a principled approach. Stata J 7: 45-70.

Schmidt LS, Grell K, Frederiksen K, Johansen C, Schmiegelow K, Schüz J. (2009) Seasonality of birth in children with central nervous system tumours in Denmark, 1970-2003. Br J Cancer 100: 185-187.

Stanton WR, Chakma B, O'Riordan DL, Eyeson-Annan M. (2000) Sun exposure and primary prevention of skin cancer for infants and young children during autumn/winter. Aust N Z J Public Health 24: 178-184.

Staykov D, Radespiel-Tröger M, Meyer M, Petsch S, Schwab S, Handschu R. (2009) Birth month and risk of glioma in adults: a registry-based study in Bavaria. Chronobiol Int 26: 282-292.
Ueda P, EdstedtBonamy AK, Granath F, Cnattingius S. (2013) Month of birth and mortality in Sweden: a nation-wide population-based cohort study. PLoS One 8(2): e56425.

Van Laar M, Kinsey SE, Picton SV, Feltbower RG. (2013) First description of seasonality of birth and diagnosis amongst teenagers and young adults with cancer aged 15-24 years in England,1996-2005. BMC Cancer 13: 365.

Walter SD, Elwood JM. (1975) A test for seasonality of events with a variable population at risk. Br J Prev Soc Med 29: 18-21.

WHO (1992) International Statistical Classification of Diseases and Related Health Problems, Tenth Revision ICD-10. World Health Organization: Geneva.

Yuen J, Ekbom A, Trichopoulos D, Hsieh CC, Adami HO. (1994) Season of birth and breast cancer risk in Sweden. Br J Cancer 70: 564-568.

Zerbo O, Iosif AM, Delwiche L, Walker C, Hertz-Picciotto I. (2011) Month of conception and risk of autism. Epidemiology 22: 469-475.

(c) (i) (2) (2) This work is licensed under the Creative Commons (c) ${ }_{\text {BY NC }}$ SA Attribution-NonCommercial-Share Alike 3.0 Unported License. To view a copy of this license, visit http://creativecommons. org/licenses/by-nc-sa/3.0/

Supplementary Information accompanies this paper on British Journal of Cancer website (http://www.nature.com/bjc) 